\title{
SWIFT BAT LOOP HEAT PIPE THERMAL SYSTEM CHARACTERISTICS AND GROUND/ FLIGHT OPERATION PROCEDURE
}

\author{
Michael K. Choi \\ NASA Goddard Space Flight Center \\ Greenbelt, MD 20771
}

\begin{abstract}
The SWIFT Burst Alert Telescope (BAT) Detector Array has a total power dissipation of $208 \mathrm{~W}$. To meet the stringent temperature gradient and thermal stability requirements in the normal operational mode, and heater power budget in both the normal operational and safehold modes, the Detector Array is thermally well coupled to eight constant conductance heat pipes (CCHPs) embedded in the Detector Array Plate (DAP), and two loop heat pipes (LHPs) transport heat from the CCHPs to a radiator. The CCHPs have ammonia as the working fluid and the LHPs have propylene as the working fluid. Precision heater controllers, which have adjustable set points in flight, are used to control the LHP compensation chamber and Detector Array XA1 ASIC temperatures. The radiator has the AZ-Tek AZW-LA-II low-alpha white paint as the thermal coating and is located on the anti-sun side of the spacecraft. This paper presents the characteristics, ground operation and flight operation procedures of the LHP thermal system.
\end{abstract}

\section{INTRODUCTION}

The BAT is the primary instrument on the SWIFT spacecraft. The SWIFT mission is part of the National Aeronautics and Space Administration (NASA) SWIFT spacecraft Medium-Size Explorer (MIDEX) Program, and is managed by Goddard Space Flight Center (GSFC). It is designed to detect gamma ray burst over a broad region of the sky in a low Earth orbit of 600 $\mathrm{km}$ altitude and quickly align the telescopes on the spacecraft to the gamma ray source. It is scheduled to launch in January 2004. The SWIFT mission is a first of its kind of multi-wavelength transient observatory for gamma ray burst astronomy. Its mission life is 3 years. The inclination is $22^{\circ}$ maximum. The spacecraft bus voltage to the instruments is in the $24 \mathrm{~V}$ to $35 \mathrm{~V}$ range. The instruments will be turned off when the voltage is below $27 \mathrm{~V}$.

The BAT is being developed at GSFC. The telescope assembly consists of 256 Detector Modules (DMs) in the Detector Array. There are 16 Detector Árray Biocks. Each Block holds 16 DMís, 3 Block
Voltage Regulator (BVR) units and 3 Block Command \& Data Handling $(\mathrm{BCDH})$ units. The power dissipation of each Block has been measured to be $13 \mathrm{~W}$. Therefore the total power dissipation of the 16 Blocks is $208 \mathrm{~W}$. The DAP is $1.3 \mathrm{~m}(4.3 \mathrm{ft}) \times 1 \mathrm{~m}(3.3 \mathrm{ft})$, accommodates all the 16 Blocks. It also provides the mounting surface and the positional stability for the Blocks. The DMs are located at the top ( $+\mathrm{X}$ side) of the DAP and is enclosed by graded- $Z$ shields on the sides and a coded mask at the top. The BVRs and BCDHs are located at the bottom (-X side) of the DAP. Blocks A, 17, 5, 6, 10, 7, 16 and 15 are at the front ( $Z$ side or radiator side) of the DAP. Blocks 3, 4, 8, 9, 13, 14, 11 and 12 are located at the rear $(+Z$ side) of the DAP. Figure 1 shows the BAT telescope assembly.

Figure 1. BAT Telescope Assembly.

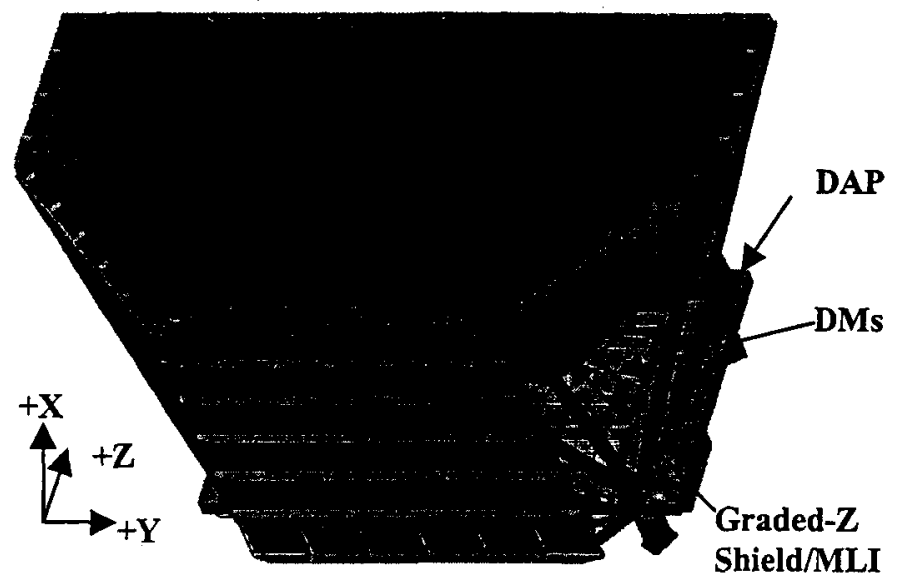

A BAT telescope assembly thermal system design concept using two propylene LHPs external to the graded- $Z$ shield/MLI enclosure was presented by Choi (1). It also included the use of precision electronics heater controllers with adjustable set points in flight to control the temperature of the LHPs and Blocks. The design concept has been turned into reality. The $-Y$ and $+Y$ side of the DAP has been extended $8.89 \mathrm{~cm}(3.5$ inch) to accommodate one LHP on each. Two propylene LHPs have been built and tested. AZW-LAII white paint has been successfully applied to the radiator. The LHPs and radiator have been integrated into the telescope assembly. Heater controllers for the 
LHPs and Blocks have been built and installed to the telescope assembly. The telescope assembly has passed the mechanical vibration test, which is part of the environmental test program. A thermal balance test on the telescope assembly was completed in early June 2003. An instrument thermal vacuum test is scheduled for late June 2003.

\section{LHP THERMAL SYSTEM CHARACTERISTICS}

Both LHPs on the BAT are external to the telescope assembly and within the sun avoidance zone so that they are cold biased. Due to non-symmetry, the equivalent sink temperature of LHP \#1, which is on the $+Y$ side, is colder than that of LHP \#2, which is on the $-Y$ side. Each LHP has a variable conductance heat pipe (VCHP). The VCHP provides a rough temperature control by pre-conditioning the LHP liquid line through a heat exchanger, which is swaged over the VCHP condenser. The top half of the compensation chamber and entire VCHP reservoir of each LHP have $0.127 \mathrm{~mm}$ (5-mil) thick silver teflon as the thermal coating.

The LHP evaporators are mounted to the bosses of the CCHPs embedded in the DAP using Cho-therm as the thermal interface material. The Blocks are also mounted to the CCHP flanges. As a result the LHP evaporators are thermally well coupled to the Blocks. The CCHPs minimize the temperature gradient between Blocks. The two LHPs share the heat dissipation of the Blocks. The LHP condensers are mounted to the backside of a radiator.

Because the LHP evaporator is limited to 45.72 $\mathrm{cm}$ (18 inch) long, it has no direct mounting interface with three of the eight CCHPs embedded in the DAP. Each LHP has two header CCHPs to augment heat transfer from the embedded CCHPs to the LHP evaporator.

To ensure temperature uniformity for the CCHPs embedded in the DAP so as to minimize the temperature gradient between the Blocks, the evaporator of LHP \#1 directly above the boss of CCHP \#5 and the evaporator of LHP \#2 directly above the boss of CCHP \#4 are shimmed. Shimming provides a gap, which is filled with G-10 and serves the purpose of thermal isolation. As a result, the evaporator of LHP \#1 has direct contact with CCHPs \#1-\#4 only, and the evaporator of LHP \#2 has direct contact with CCHPs $\# 5$-\#8 only.

The two LHP compensation chambers are cold biased so that they are actively controlled by heaters and heater controllers to the required temperature in the normal operational mode. The two VCHP reservoirs are also cold biased so that they are actively controlled by heaters and heater controllers to the required temperature. Adjustable set points are required in flight for the heater controllers. Heater controllers have been built and tested at GSFC to meet this requirement. The Power Converter Box (PCB) supplies adjustable voltage signals with high impedance, in the $0 \mathrm{~V}$ to $5 \mathrm{~V}$ range, to the heater controllers to change the temperature set points in the $-15^{\circ} \mathrm{C}$ to $+25^{\circ} \mathrm{C}$ range in flight. Command is sent from the ground.

For the LHP to work, the temperature of VCHP reservoir is required to be $5^{\circ} \mathrm{C}$ colder than the LHP compensation chamber when the compensation chamber is $+5^{\circ} \mathrm{C}$. For colder set points, a larger offset is required, and for hotter set points a smaller offset is required. The offset as a function of the compensation chamber set point is presented in Figure 2. Also the controller for the VCHP works "in reverse" (i.e., off when the VCHP temperature feedback to the controller is below the set point, and on when it is above the set point). The heater controller developed at GSFC for the LHPs has a primary side (Side A) and a redundant side (Side B). Each side has three control units. Two control units control two separate heater circuits on one compensation chamber, and the third control unit controls a heater circuit on the VCHP reservoir. The third control unit also meets the offset requirement and works "in reverse".

Figure 2. Offset as a Function of Compensation Chamber Set point.

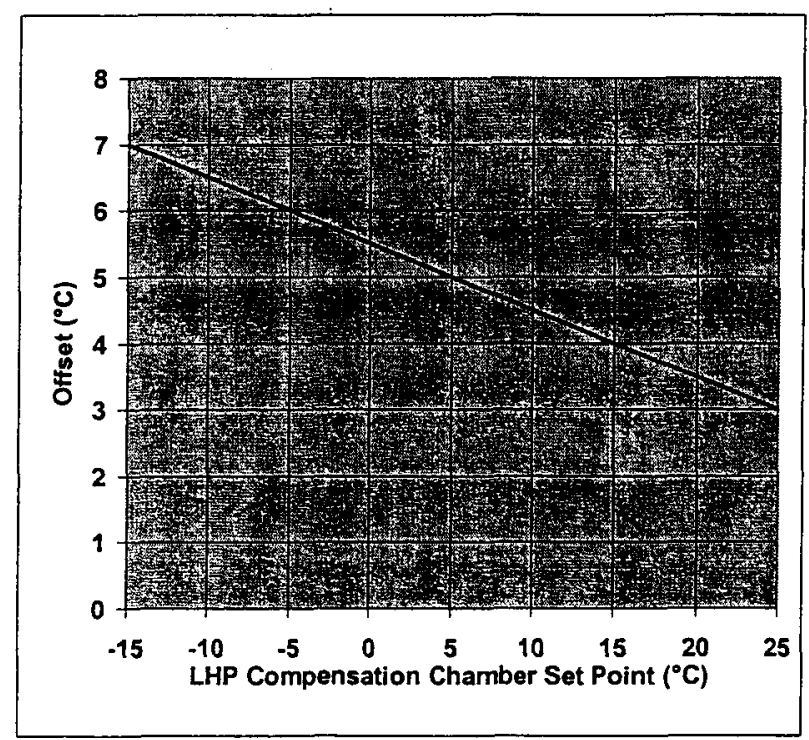

Figure 3 shows the heater circuits for each LHP controlled by the either primary or redundant side of the heater controller. Each heater circuit on the compensation chamber has a $97.2 \Omega$ Kapton film heater attached to it by STYCAST and a YSI 44910 thermistor attached to it by a $50 \%$ boron nitride and $50 \%$ uralane mixture (see Figure 4). STYCAST is $2850 \mathrm{FT}$ with Cat 9. The heater power per eircuit is $7.5 \mathrm{~W}$ at $27 \mathrm{~V}$. The heater circuit on the VCHP reservoir has a $145.8 \Omega$ 
Kapton film heater attached to it by STYCAST and a YSI 44910 thermistor attached to the VCHP reservoir liquid return line by a $50 \%$ boron nitride and $50 \%$ uralane mixture. The heater power is $10 \mathrm{~W}$ at $27 \mathrm{~V}$. There are two heater controllers -- one for each LHP. They are mounted to the bottom of the DAP and are directly underneath the LHPs.

Figure 3. LHP Operating Mode Heater Circuit.

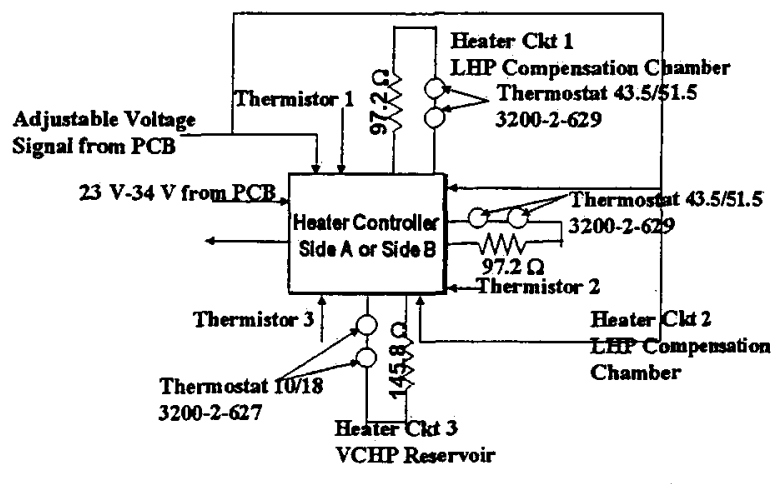

Figure 4. LHP Compensation Chamber.

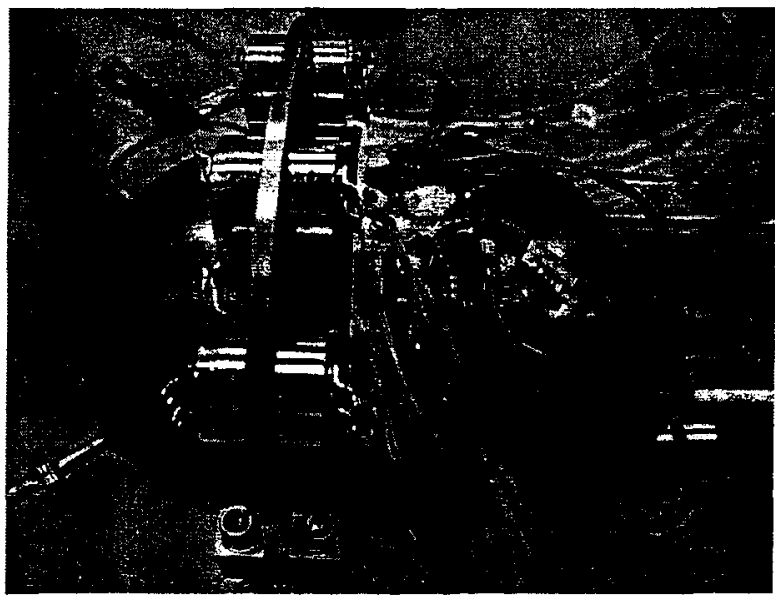

For each LHP, there is a power switch for the heater controller primary side and one for the redundant side. Therefore the total number of power switches for the LHP heater controllers is four. This redundancy allows either the primary or redundant heater circuit on one LHP to be disabled without affecting the other LHP, if there is a heater circuit failure. The BAT PCB contains the power switches.

To prevent overheating due to a heater controller fail-on scenario, there are two redundant overtemperature protection mechanical thermostats in series in each heater circuit. The thermostats on the LHP compensation chamber have a set point of $43.5^{\circ} \mathrm{C}$ closed and $51.5^{\circ} \mathrm{C}$ open. They are attached to a thermostat saddle by STYCAST. The saddle is attached to the compensation chamber by Nusil CV2946. The thermostats on the VCHP reservoir have a set point of $18^{\circ} \mathrm{C}$ closed and $23^{\circ} \mathrm{C}$ open. They are attached to a thermostat saddle by STYCAST. The saddle is also attached to the compensation chamber by STYCAST.

Before the BAT is turned on after launch or after a safehold mode, startup of the LHPs is required to ensure that propylene circulates in the LHPs to transport heat from the evaporator to the condenser. Startup is performed for one LHP at a time. For each LHP, there is a primary startup heater circuit and a redundant startup heater circuit. Each circuit has three VISHAY part number RER50F39R2R 39.2-ohm resistors in parallel. The heater power per circuit is $56 \mathrm{~W}$ at $27 \mathrm{~V}$. The resistors are attached to a heater bracket by using STYCAST. The bracket is also attached to the LHP evaporator by using STYCAST (see Figure 5). It is also mechanically held to the evaporator to unsure that it won't detach. There are two redundant overtemperature protection mechanical thermostats in series in each startup heater circuit. The thermostat has a set point of $47^{\circ} \mathrm{C}$ closed and $55^{\circ} \mathrm{C}$ open. The thermostats are attached to the evaporators by using STYCAST.

Figure 5. LHP Startup Heater Bracket.

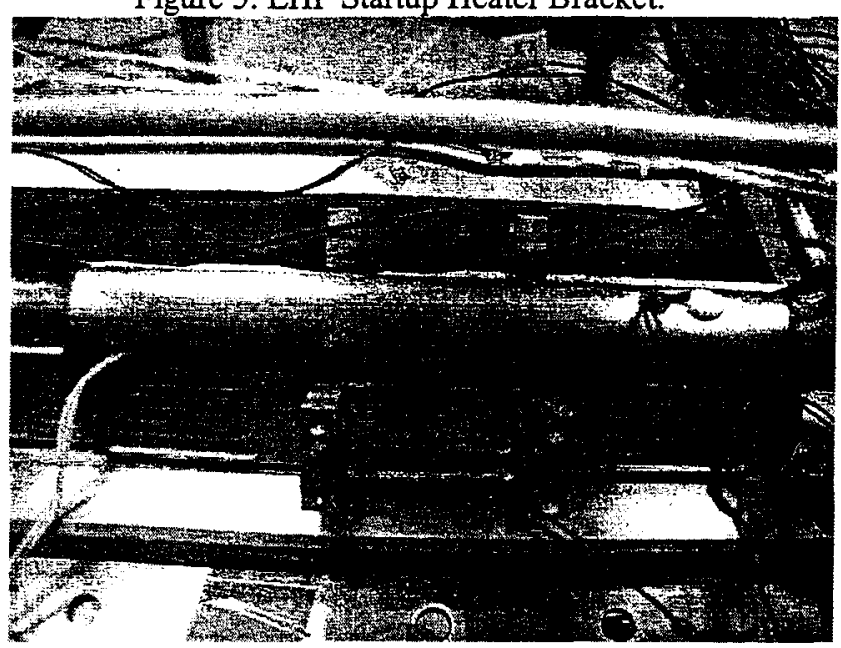

For each LHP, there is a power switch for the primary startup heater circuit and one for the redundant startup heater circuit. Therefore the total number of power switches for the startup heaters is four. This redundancy allows either the primary or redundant startup heater circuit on one LHP to be disabled without affecting the other LHP, if there is a heater circuit failure. The power switches are commanded on/off from the ground. The BAT PCB contains the power switches.

To neet the temperature gradient and themal stability requirements of the XA1 ASIC and CZT 
detectors, a $3000 \Omega$ Kapton heater is attached to the housing exterior of the each of the eight dual-DM boxes on each Block using Y966 transfer adhesive. The heaters are connected in parallel and have redundancy. A YSI 44910 thermistor feeds temperature back to a precision heater controller. The thermistors are attached to the DM housing exterior using a $50 \%$ boron nitride and $50 \%$ uralane mixture. Adjustable set points are required in flight for the heater controllers. Heater controllers have been built and tested at GSFC to meet this requirement. The PCB supplies voltage for power and adjustable voltage signals with high impedance, in the $0 \mathrm{~V}$ to $5 \mathrm{~V}$ range, to the heater controllers to change the temperature set points in the $-15^{\circ} \mathrm{C}$ to $+25^{\circ} \mathrm{C}$ range in flight. Command is sent from the ground. There is a heater controller per Block. Heater controllers for the Blocks on the $-Z$ side are located at the $-Z$ side of the DAP. Heater controllers for the Blocks on the $+Z$ side are located at the $+Z$ side of the DAP. Each heater controller has a primary side (Side A) and a redundant side (side B). Each side has four separate control units. One adjustable voltage signal from the $\mathrm{PCB}$ changes the temperature set points of all the four control units. There is a primary power switch and a redundant power switch for a pair of Blocks. If any of the primary heater circuits fails or the power switch for the primary heater circuits fails, the redundant power switch will be used. The PCB contains the power switches.

When the startup heaters are turned on, heat transfers from the LHP evaporators to the CCHPs embedded in the DAP. The CCHPs transfer heat to the Detector Array. The time required for the LHP startup mode is dependent on the thermal mass and initial temperature of the Detector Array and DAP. The flight temperature telemetry of the LHP evaporators, compensation chambers, and DM Blocks are criteria to manually command the startup heaters off. Ground testing and the first startup after launch will provide data of the time and temperature required for the startup mode. Telescope assembly thermal balance test data showed that startup time (from start of compensation chamber control to end of startup) is up to 12 hours. After startup is completed, a command from the ground to the PCB is needed to turn off the startup heaters. Results of LHP component thermal vacuum performance verification test and telescope assembly thermal balance test have validated the startup heater design.

Each LHP has a primary survival heater circuit and a redundant survival heater circuit on the compensation chamber. Survival heater circuits provide LHP shutdown when the BAT is non-operating. A survival heater circuit consists of a Kapton heater and two mechanical thermostats in series. The heaters are attached to the compensation chamber by STYCAST. The thermostats are attached to a thermostat saddle, which is attached to the compensation chamber by STYCAST. The primary thermostats have a set point of $-8^{\circ} \mathrm{C}$ closed and $-3^{\circ} \mathrm{C}$ open. The redundant thermostats have a set point of $-13^{\circ} \mathrm{C}$ closed and $-8^{\circ} \mathrm{C}$ open. To ensure that the LHPs shut down when the BAT is not operating, the survival heater circuits on the DAP also have the same thermostat set points.

The LHPs shut down during the launch, ascent and early orbit phase, the spacecraft checkout phase, and safehold mode. Survival heaters are powered by spacecraft bus survival power switches. Unless chosen not to be on, the primary and redundant survival heater power switches are turned on all the time, including launch, ascent, early orbit, spacecraft check out phase, normal operating and safehold. If only the redundant survival heater circuits on the LHPs are enabled, only the redundant survival heater circuit on the DAP is enabled so that the DAP is no warmer than the compensation chambers. For the same reason, if only the primary survival heater circuits on the LHPs are enabled, either the primary or redundant survival heater circuit on the DAP are enabled

\section{FLIGHT OPERATION PROCEDURE}

\section{Flight Temperature Telemetry}

Flight temperature telemetry will be used to operate the LHP thermal system in orbit. In the normal operation mode, the PCB provides housekeeping temperature telemetry for the following LHP components:

-Evaporators (two each).

- Compensation chambers (one each).

- Condensers (two each).

-Liquid lines at inlet to compensation chambers (one each).

- Liquid lines at outlet of condensers (one each).

-Vapor lines at outlet of evaporators (one each).

- Vapor lines at inlet of condensers (one each).

The PCB also provides housekeeping temperature telemetry for 2 locations on the DM housing. The $\mathrm{BCDH}$ provides housekeeping temperature telemetry for each XA1 ASIC. The LHP compensation chamber heater controller set point is adjusted to meet the XA1 ASIC temperature requirement. In the safehold mode, the BAT is turned off and housekeeping temperature telemetry will be unavailable.

The spacecraft bus provides limited temperature telemetry for the following LHP components:

- Compensation chambers (one each).

-Evaporators (one).

It also provides temperature telemetry for the following components:

-Radiator (one)

-DAP (one). 
-DM housing (one).

Spacecraft bus temperature telemetry will be available in both normal operation mode and safehold mode. In the safehold mode, it is necessary to use the telemetry to verify that the LHPs shut down, and the Blocks and DAP are within cold survival temperature limit.

\section{LHP Startup}

There are four power switches allocated to the LHP startup heaters - one primary (Side A) and one redundant (Side B) for each LHP. Each LHP starts up independently (i.e., one at a time). The primary power switch will be commanded on. If a primary power switch fails, the redundant switch will be commanded on.

The LHP startup heaters have over-temperature protection by two mechanical thermostats in series with the heater circuit. If there is no flight temperature telemetry for an extended period of time (i.e. during a pass) during the startup mode, and the temperature of the LHP evaporators reach $55^{\circ} \mathrm{C}$, the over-temperature thermostat will switch the heater circuit to open. Each of the LHPs has two over-temperature protection thermostats in series with the startup heater in either the primary startup heater or redundant startup heater circuit. The thermostats are located at the evaporator. The set point of the thermostats is $47^{\circ} \mathrm{C}$ closed and $55^{\circ} \mathrm{C}$ open. Also there are two over-temperature protection thermostats in series with the operating mode heater in either the primary operating mode heater or redundant operating mode heater circuit. The thermostats are located at the compensation chamber. The set point of the thermostats is $43.5^{\circ} \mathrm{C}$ closed and $51.5^{\circ} \mathrm{C}$ open. The purpose of over-temperature protection thermostats is to prevent propylene in the LHPs from exceeding the hot survival temperature limit. In flight the LHP startup heaters can be turned on or off by a command from the ground to the PCB only. If the startup heater is turned on to perform a startup, and then flight temperature telemetry and command to the spacecraft are unavailable due to the realities of ground station coverage, the over-temperature protection thermostats will prevent LHPs from overheated. If the LHP has started up when flight temperature telemetry and command to the spacecraft are unavailable, and the startup heater is still tumed on, the LHP will transport heat from the Detector Array Blocks to the radiator and is thermally acceptable. The Blocks will be turned on gradually when command to the spacecraft is available. The startup heater will be turned off when flight temperature telemetry and command to the spacecraft are available again. Therefore Lrip turn-on has no time-critical issues caused by the realities of ground station coverage.
At the end of the Spacecraft Checkout Phase or safehold mode, a LHP startup procedure needs to be performed. This procedure has been verified during the telescope assembly thermal balance test. Thermal balance test results show that the temperature gradient between the LHP compensation chamber heat controller set point and XA1 ASIC is $11^{\circ} \mathrm{C}$. The LHP compensation chamber heater controller set point is therefore $11^{\circ} \mathrm{C}$ colder than the XA1 ASIC temperature that the BAT scientist requires. Assuming an $11^{\circ} \mathrm{C}$ XA1 ASIC temperature is required, the LHP startup procedure is as follows:

1) During the LHP startup mode, pre-heating of the LHP compensation chambers and VCHP reservoirs is performed first. The power switch for the primary (Side A) operating mode heater controller for LHP \#1 is turned on and a set point of $0^{\circ} \mathrm{C}$ is made. The primary operating mode heater controller for LHP \#2 is turned on and a set point of $10^{\circ} \mathrm{C}$ is made.

2) After pre-heating (i.e. when the compensation chamber temperature reaches heater controller set point), the primary (Side A) startup heater on LHP \#1 is commanded on. The operational heaters on the LHP compensation chambers and VCHP reservoirs remain enabled.

3) All the 16 power switches ( 8 primary and 8 redundant) for the Block heater controllers are turned on, and the set-points of all the heater controllers for the primary and redundant heater circuits on the Blocks are set to $11^{\circ} \mathrm{C}$, so that the heat dissipation is $60 \mathrm{~W}$ at $27 \mathrm{~V}$.

4) When LHP \#1 has started up (i.e., circulating propylene to condensers), as evidenced by flight temperature telemetry, 4 Blocks $(A, 17,3,4)$ are turned on, adding $52 \mathrm{~W}$ power dissipation.

5) The redundant power switches for the Block heaters are turned off. Power requirement is decreased by 30 $\mathrm{W}$ at $27 \mathrm{~V}$.

6) Eight Blocks $(5,6,8,9,7,10,13,14)$ are turned on, adding $104 \mathrm{~W}$ power dissipation.

7) Wait until temperatures of Blocks have begun to flatten out $\left(<0.5^{\circ} \mathrm{C} / \mathrm{hr}\right)$.

8) Startup of LHP \#1 is completed and startup heater on LHP \#1 is commanded off.

9) Operating mode heater controller for LHP \#2 is changed to $0^{\circ} \mathrm{C}$ in one increment.

10) When LHP \#2 compensation chamber reaches heater controller set point, primary (Side A) startup heater on LHP \#2 is commanded on. The operational heaters on the LHP compensation chambers and VCHP reservoirs remain enabled.

11) When LHP \#2 has started up (i.e., circulating propylene to condensers), as evidenced by flight temperature telemetry, the power switch for the primary startup heater on LHP \#2 is commanded off. Startup of both LHPs is completed. 
12) Four more Blocks $(11,12,15,16)$ are turned on such that all the Blocks are turned on.

13) The set points of the heater controllers for the Blocks and LHP compensation chambers are adjusted to meet the XA1 ASIC temperature requirement by sending commands from the ground to the PCB. To prevent LHP shutdown or cold shocks, set point is changed in $1^{\circ} \mathrm{C}$ increments and it is necessary to wait until the Block temperatures have begun to flatten out at $0.5^{\circ} \mathrm{C} / \mathrm{hr}$ before making another change.

The above procedure has been verified in the BAT telescope assembly thermal balance test.

\section{COOLING DURING GROUND OPERATION}

An air plenum cooling system is used to cool the Detector Array during Long Form Functional Test (LFFT) which is 5 hour or longer. It consists of a PAC air conditioning unit, HEPA filters, a defrost timer, flexthane air ducts with insulation, plenum box and manifolds. The plenum box is attached to the radiator. The manifolds are attached to the plenum box. The air flow rate is about $590 \mathrm{cfm}$. Air supplied by the PAC is filtered by the HEPA filters before it enters the inlet manifold of the plenum box and flows over the radiator white paint. Then it exits the outlet manifold of the plenum box and returns to the PAC. A small fraction of the air flow is diverted from the plenum inlet manifold to cool the LHP compensation chambers. The LHPs transport heat from the Detector Array to the radiator. Using a defrost timer, ice buildup on the PAC cooling coils is prevented and cooling is optimized. The temperature of air entering the plenum manifold is approximately $7^{\circ} \mathrm{C}$. There has been no condensation. The step-by-step procedure of operating the air plenum cooling system is as follows:

1) Turn on PAC unit.

2) Set PAC evaporator and cooling fan to $40^{\circ} \mathrm{F}\left(4.4^{\circ} \mathrm{C}\right)$.

3) Turn on primary power switch for LHP compensation chamber operating mode heater controllers, and set heater controllers to $12^{\circ} \mathrm{C}$.

4) Turn on power switch for primary startup heaters for each LHP.

5) Turn the Blocks on.

6) Two hours after all the Blocks are turned on, turn off the power switches for the startup heaters.

At a $12^{\circ} \mathrm{C}$ set point for the heater controllers, the XAl ASIC temperatures are maintained at $21^{\circ} \mathrm{C}$ to $22^{\circ} \mathrm{C}$, which is acceptable to the BAT scientist. Without the air plenum cooling system, the XA1 ASIC reached $36^{\circ} \mathrm{C}$ after the instrument was turned on for five hours during the vibration test when the air plenum cooling system was not permitted.
Figure 6. Air Plenum PAC and HEPA Filters.

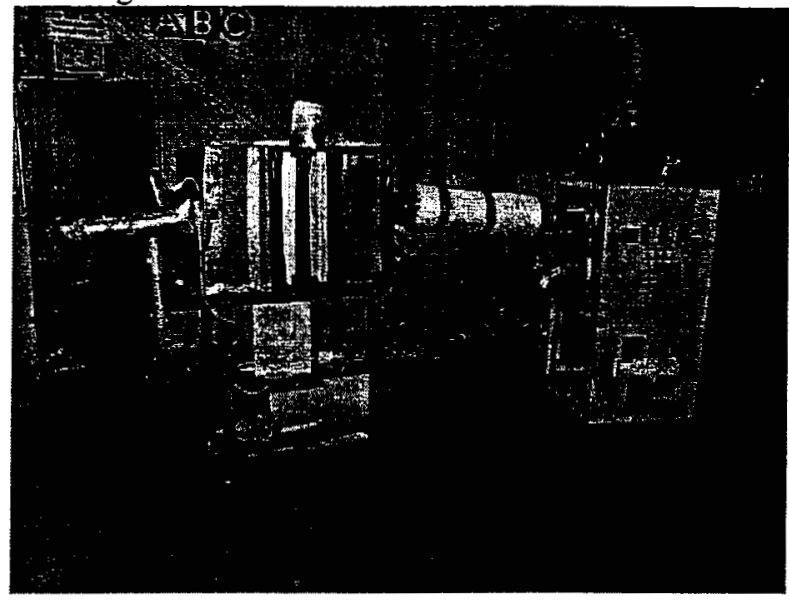

Figure 7. Air Plenum Box, Manifolds and Air Ducts.

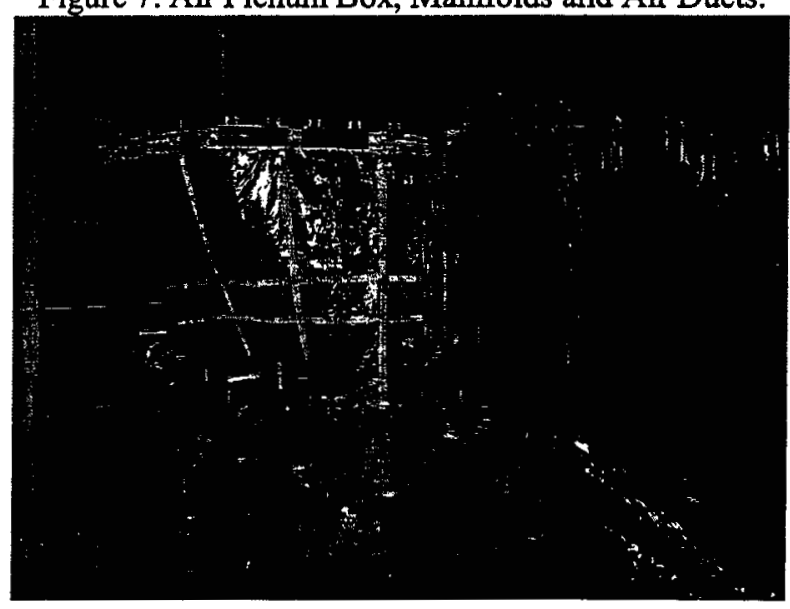

\section{THERMAL VACUUM CYCLING OF BLOCKS}

Thermal vacuum $(\mathrm{T} / \mathrm{V})$ cycling tests from $-20^{\circ} \mathrm{C}$ to $+25^{\circ} \mathrm{C}$ were performed at the Block component level. LFFT was performed at intermediate hot plateaus of $+15^{\circ} \mathrm{C}$ and intermediate cold plateaus of $-10^{\circ} \mathrm{C}$ in Cycle $\# 1$ and Cycle \#4 to compare the functional performance before and after the $\mathrm{T} / \mathrm{V}$ cycles. Aliveness test was performed at cold soaks of $-20^{\circ} \mathrm{C}$ and hot soaks of $+25^{\circ} \mathrm{C}$. Four $\mathrm{T} / \mathrm{V}$ cycles for the Detector Array are required at the instrument level $\mathrm{T} / \mathrm{V}$ test, which will include the PCB and Image Processor Electronics (IPE). The chamber shroud is the heat sink for the LHPs. The cryopanel in front of the radiator is the heat sink for the radiator. The PCB and IPE are mounted and thermally well coupled to 2 different cold plates connected in series. The chamber shroud, cryopanel and cold plates are cooled by gaseous nitrogen in the test facility. Figure 8 shows the test setup.

Telescope assembly thermal balance test results show that a $+25^{\circ} \mathrm{C}$ hot soak temperature can be achieved by running both LHPs with $\mathrm{a}+14^{\circ} \mathrm{C}$ set point on the LHP heater controllers and $a+25^{\circ} \mathrm{C}$ set point on 
the Block heater controllers. Thermal balance test results also show that with $\mathrm{a}-11^{\circ} \mathrm{C}$ set point for the LHP heater controllers, the LHPs running, and the survival heaters and Block heaters disabled, the coldest temperature achieved for the Block housing is $-3^{\circ} \mathrm{C}$. Therefore the cold soak and intermediate cold plateau for the Blocks will be $-3^{\circ} \mathrm{C}$. Figure 9 shows the $\mathrm{T} / \mathrm{V}$ test profile. Temperatures are monitored by control thermocouples located at the housing exterior of the DM's.

Figure 8. BAT Instrument T/V Test Setup.

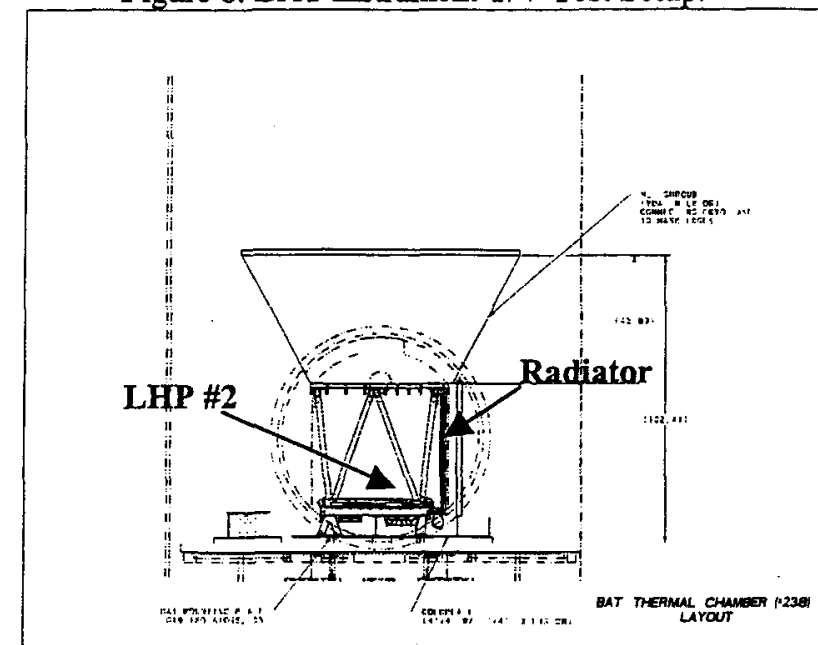

Figure 9. BAT Instrument T $N$ Test Profile.

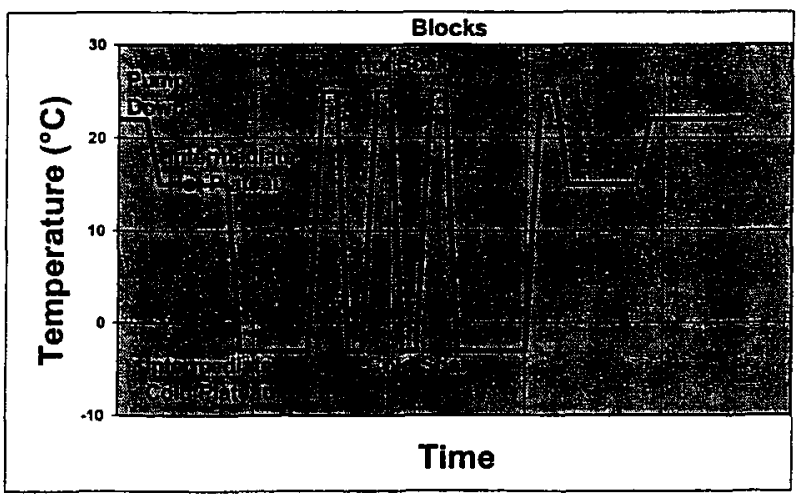

The following step-by-step procedure for $\mathrm{T} / \mathrm{V}$ Cycle \#1 illustrates how the T/V test will be performed:

Transition from Pumpdown to Intermediate Hot Plateau 1) Start transition to intermediate hot plateau. Enable all flight primary survival heaters first and adjust voltage to $27 \mathrm{~V}$.

2) Set controls for the shroud and radiator cryopanel to $-43^{\circ} \mathrm{C}$ and $-97^{\circ} \mathrm{C}$ respectively.

3) Verify both LHPs shutdown.

4) Turn on $P C B$ and IPEs.

4) Enable all primary heater controllers on both LHPs and adjust the voltage to $27 \mathrm{~V}$.
5) Set operating mode heater controller of LHP \#1 to $4^{\circ} \mathrm{C}$.

6) Set operating mode heater controller of LHP \#2 to $4^{\circ} \mathrm{C}$.

7) Enable all primary and redundant operating mode heater controllers on the Blocks and set the heater controllers to $+15^{\circ} \mathrm{C}$

8) When LHP \#1 compensation chamber and LHP \#2 compensation chamber reach $4^{\circ} \mathrm{C}$, turn on primary startup heaters on LHP \#1 and LHP \#2 and adjust voltage to $27 \mathrm{~V}$.

9) Verify startup of LHP \#1.

10) Verify startup of LHP \#2.

11) Turn on all 16 Blocks.

12) Wait until temperatures of Blocks have begun to flatten out.

13) Turn off primary startup heaters on LHP \#1 and LHP \#2.

14) Adjust set points of operating mode heater controllers of LHPs at $1^{\circ} \mathrm{C}$ increment, if needed, so that the Block control thermocouples are within $\pm 2^{\circ} \mathrm{C}$ of the nominal hot plateau goal. Wait for 30 minutes before adjusting LHP heater controller set point again.

15) If a LHP shuts down, turn on primary startup heaters on that LHP. Verify LHP startup and turn off primary startup heater.

16) Adjust control for cold plates for the PCB and IPEs so that PCB and IPE control thermocouples are within $\pm 2^{\circ} \mathrm{C}$ of the nominal hot plateau goals.

Transition from Intermediate Hot Plateau to Intermediate Cold Plateau

1) Set controls for the shroud and radiator cryopanel to $-85^{\circ} \mathrm{C}$ and $-117^{\circ} \mathrm{C}$ respectively.

2) Disable all Block heater controllers.

3) Decrease set point of operating mode heater controllers on LHPs to $-11^{\circ} \mathrm{C}$ at $1^{\circ} \mathrm{C}$ increment. Wait for 30 minutes before adjusting LHP heater controller set point again. If a LHP shuts down, turn on primary startup heaters on that LHP.

4) Set controls for test heaters on PCB and IPEs to $-10^{\circ} \mathrm{C}$.

5) Decrease control for PCB and IPE cold plates so that PCB and IPE control thermocouples are within $\pm 2^{\circ} \mathrm{C}$ of intermediate cold plateau goals.

Transition from Intermediate Cold Plateau to Cold Soak 1) Start transition to cold soak \#1. Set controls for test heaters on PCB and IPEs to $-20^{\circ} \mathrm{C}$.

2) Decrease control for PCB and IPE cold plates so that PCB and IPE control thermocouples are within $\pm 2^{\circ} \mathrm{C}$ of the cold soak goals.

\section{Transition from Cold Soak to Hot Soak}

1) Start transition to hout soak \#1, set controls for the shroud and radiator cryopanel to $-43^{\circ} \mathrm{C}$ and $-97^{\circ} \mathrm{C}$ respectively. 
2) Set control for test heaters on $\mathrm{PCB}$ to $55^{\circ} \mathrm{C}$ and percent peak power such that rate won't exceed $30^{\circ} \mathrm{C} / \mathrm{hr}$. 3) Set control for test heaters on IPE to $50^{\circ} \mathrm{C}$ and percent peak power such that rate won't exceed $30^{\circ} \mathrm{C} / \mathrm{hr}$. 4) Enable all primary and redundant operating mode heater controllers on the Blocks and set the heater controllers to $+25^{\circ} \mathrm{C}$ and adjust the voltage to $35 \mathrm{~V}$.

5) Enable all flight primary survival and adjust the voltage to $35 \mathrm{~V}$.

6) Enable all primary heater controllers on both LHPs and adjust the voltage to $35 \mathrm{~V}$.

7) Disable all redundant heater controllers on both LHPs.

8) Increase set point of operating mode heater controllers on LHPs to $14^{\circ} \mathrm{C}$ at $1^{\circ} \mathrm{C}$ increment. Wait for 30 minutes before adjusting LHP heater controller set point again.

9) If a LHP shuts down, turn on primary startup heaters on that LHP. Verify LHP startup, and turn off startup heater.

10) If needed, increase set point of PCB and IPE test heater controls, and increase control for PCB and IPE cold plates so that the PCB and IPE control thermocouples are within $\pm 2{ }^{\circ} \mathrm{C}$ of the hot soak goals

\section{Transition from Hot Soak to Cold Soak}

1) Set controls for the shroud and radiator cryopanel to $-85^{\circ} \mathrm{C}$ and $-117^{\circ} \mathrm{C}$ respectively.

2) Disable all Block heater controllers.

3) Decrease set point of operating mode heater controllers on LHPs to $-11^{\circ} \mathrm{C}$ at $1{ }^{\circ} \mathrm{C}$ increment. Wait for 30 minutes before adjusting LHP heater controller set point again. If a LHP shuts down, turn on primary startup heaters on that LHP.

4) Set controls for test heaters on PCB and IPEs to $-20^{\circ} \mathrm{C}$.

5) Decrease control for PCB and IPE cold plates so that $\mathrm{PCB}$ and IPE control thermocouples are within $\pm 2^{\circ} \mathrm{C}$ of intermediate cold plateau goals.

\section{SUMMARY AND CONCLUSIONS}

Two propylene LHPs have been built and tested for the BAT telescope assembly. Each LHP has an ammonia VCHP that provides a rough temperature control by pre-conditioning the LHP liquid line. The DAP has been extended on the $+Y$ and $-Y$ sides to accommodate the LHPs outside the graded- $Z$ shields/MLI so that the LHPs are cold biased. The evaporator of LHP \#1 directly above the boss of CCHP \#5 and the evaporator of LHP \#2 directly above the boss of CCHP \#4 are shimmed. As a result, the evaporator of LHP \#1 has direct contact with CCHPs $\# 1-\# 4$ only, and the evaporator of LHP \#2 has direct contact with CCHPs \#5-\#8 only. Two ammonia header CCHPs augment heat transfer from the CCHPs embedded in the DAP to the LHPs. AZ-Tek's AZWLA-II low-alpha white paint has been successfully applied to the radiator. The LHPs and radiator have been integrated into the telescope assembly. Heater controllers for the LHPs and Blocks have been built, tested and installed to the telescope assembly. They have adjustable set points in flight. A thermal balance test on the telescope assembly was completed in early June 2003. It validated the LHP thermal system design. The procedure of starting up one LHP at a time was verified in the thermal balance test. Also the procedure of changing the LHP compensation chamber heater controller set point by a $1^{\circ} \mathrm{C}$ increment and waiting for 30 minutes before making another change was verified.

An air plenum cooling system has successfully cooled the Detector Array XA1 ASIC temperature to $21^{\circ} \mathrm{C}$ to $22^{\circ} \mathrm{C}$ during LFFT. The LHPs transport heat from the Detector Array to the radiator, which is cooled by chilled air supplied by the PAC unit. A small amount of the air flow is diverted from the plenum manifold to cool the LHP compensation chambers.

A 4-cycle T/V test will be performed on the BAT instrument. Based on the telescope assembly thermal balance test results, a $+25^{\circ} \mathrm{C}$ hot soak temperature can be achieved for the Block housing by running both LHPs, a $+14^{\circ} \mathrm{C}$ set point on the LHP heater controllers and $\mathrm{a}+25^{\circ} \mathrm{C}$ set point on the Block heater controllers. With the LHPs running and the survival heaters and Block heaters disabled, a $-3^{\circ} \mathrm{C}$ cold soak can be achieved by a $-11^{\circ} \mathrm{C}$ set point on the LHP heater controllers. A detailed procedure for performing the $\mathrm{T} / \mathrm{V}$ test has been presented.

\section{REFERENCES}

1. Choi, M. K., "Thermal Design To Meet Stringent Temperature Gradient/Stability Requirements of Swift BAT Detectors," Paper No. AIAA-20002905, IECEC 2000, Las Vegas, NV, July 24-28, 2000. 